\title{
Effect of probiotic species on irritable bowel syndrome symptoms: A bring up to date meta-analysis
}

\author{
María Ortiz-Lucas ${ }^{1}$, Aurelio Tobias², Pablo Saz ${ }^{3}$ and Juan José Sebastián ${ }^{4}$ \\ ${ }^{1}$ Bachelor Degree in Biochemistry. School of Health Sciences. Universidad de San Jorge. Zaragoza, Spain. ${ }^{2}$ Institute of \\ Environmental Assessment and Water Research (IDAEA). Spanish Council for Scientific Research (CSIC). Barcelona, \\ Spain. ${ }^{3}$ School of Medicine. Universidad de Zaragoza. Zaragoza, Spain. ${ }^{4}$ Department of Gastroenterology. Hospital Royo \\ Villanova. Zaragoza, Spain
}

\section{ABSTRACT}

Background and objectives: immune system alteration in irritable bowel syndrome (IBS) patients may be modulated by probiotics. We assessed the efficacy of some probiotic species in alleviating characteristic IBS symptoms.

Material and methods: a meta-analysis of all identified randomized controlled trials comparing probiotics with placebo in treating IBS symptoms was performed with continuous data summarized using standardized mean differences (SMDs) with 95\% confidence intervals (95\% Cls), where appropriate. The random-effects model was employed in cases of heterogeneity; otherwise, fixed-effects models were used.

Results: meta-analysis was performed with 10 of 24 studies identified as suitable for inclusion. Probiotics improved pain scores if they contained Bifidobacterium breve (SMD, -0.34; 95\% CI, 0.66; -0.02), Bifidobacterium longum (SMD, -0.48; 95\% CI, 0.91 ; -0.06), or Lactobacillus acidophilus (SMD, -0.31; 95\% CI, $-0.61 ;-0.01)$ species. Distension scores were improved by probiotics containing B. breve (SMD, -0.45; 95\% CI, -0.77; -0.13), Bifidobacterium infantis, Lactobacillus casei, or Lactobacillus plantarum (SMD, -0.53; 95\% CI, -1.00; -0.06) species. All probiotic species tested improved flatulence: $B$. breve (SMD, -0.42; 95\% CI - 0.75 ;$0.10), B$. infantis, L. casei, L. plantarum (SMD, -0.60; 95\% CI, -1.07; -0.13), B. longum, L. acidophilus, Lactobacillus bulgaricus, and Streptococcus salivarius ssp. thermophilus (SMD, -0.61; 95\% CI, $-1.01 ;-0.21)$. There was not a clear positive effect of probiotics concerning the quality of life.

Conclusions: some probiotics are an effective therapeutic option for IBS patients, and the effects on each IBS symptom are likely species-specific. Future studies must focus on the role of probiotics in modulating intestinal microbiota and the immune system while considering individual patient symptom profiles.

Key words: Probiotics. Irritable bowel syndrome. Immune system. Meta-analysis.

Received: 03-09-2012

Accepted: 28-01-2013

Correspondence: María Ortiz Lucas. School of Medicine. Universidad de San Jorge. Autovía A-23 Zaragoza-Huesca, km. 299. 50830 Villanueva de Gállego. Zaragoza, Spain

e-mail: mariaortizlucas@gmail.com

\section{ABBREVIATIONS}

C: Constipation.

CG: Control group.

CI: Confidence interval.

D: Diarrhea.

IBS: Irritable bowel syndrome.

QOL: Quality of life.

SD: Standard deviation.

SMD: Standardised mean differences.

TG: Treatment group.

\section{INTRODUCTION}

Defining and treating irritable bowel syndrome (IBS) can be challenging. Among the wide variety of treatment options, probiotics appear to be one of the best options (1). Recently, growing evidence has suggested an alteration in the immune system cell profile of IBS patients and a close relationship between the immune and nervous systems $(2,3)$. Furthermore, several authors have studied the relationship between probiotic intake and blood cytokine levels (4) or changes in fecal microbiota $(5,6)$.

Several reviews and meta-analyses that have evaluated the role of probiotics in IBS therapy have concluded that probiotics appear to improve overall IBS symptoms (712). However, a meta-analysis that includes any probiotic in the evaluation of symptom relief may not be the best method for assessing the efficacy of specific probiotics (11-13). Therefore, we assessed the efficacy of each specific probiotic species in alleviating characteristic IBS symptoms.

Ortiz-Lucas M, Tobias A, Saz P, Sebastián JJ. Effect of probiotic species on irritable bowel syndrome symptoms: A bring up to date meta-analysis. Rev Esp Enferm Dig 2013;105:19-36. 


\section{METHODS}

\section{Study selection}

A deep search of the PubMed, Cochrane Library, and EMBASE databases was performed for randomized controlled trials published up until January 31, 2012. An open search was conducted using the MeSH search terms "Probiotics" and "Irritable Bowel Syndrome". If a study could not be included/excluded based on the Title/Abstract field, the full text of the article was reviewed. Furthermore, the reference lists of studies that met inclusion criteria, pertinent review articles, and meta-analyses (7-12) were sought manually to identify additional relevant publications.

\section{Selection criteria}

Randomized controlled trials meeting all of the following criteria were included:

- Comparison of the efficacy of any probiotic therapy versus placebo for patients with IBS. Both groups had to be treated equally with the exception of the probiotic therapy.

- Rome criteria I, II, or III for the diagnosis of IBS.

- Subjects were adult patients (age $\geq 18$ years).

- Study results were published in English or Spanish.

\section{Exclusion criteria}

- Studies evaluating the efficacy of a symbiotic or a prebiotic.

- Additional therapy provided to both groups (e.g., drugs).

- Crossover studies.

- Studies including pathologies other than IBS.

- Congress abstracts.

\section{Rules for selection among several effect estimates}

Many of the studies selected for this meta-analysis reported more than 1 estimated effect of the results. Each result was analyzed by grouping studies with the same result measurement and making comparisons among them for each of the probiotic species. Evaluated symptoms included abdominal pain or discomfort, bloating or distension, stool frequency, stool consistency, flatulence, straining at stool, incomplete evacuation, fecal urgency, and IBS quality of life (QOL).

Investigators provided patients with a probiotic strain mixture in most studies. Considering this fact, and to analyze the possible effect of each probiotic individually, data were collected for a probiotic species if the study contained the species listed below, regardless of whether it contained other species. The following probiotic species were evaluated: Bacillus coagulans, Bifidobacterium animalis ssp. lactis and ssp. animalis, Bifidobacterium bifidum, Bifidobacterium breve, Bifidobacterium infantis, Bifidobacterium longum, Lactobacillus acidophilus, Lactobacillus brevis, Lactobacillus bulgaricus, Lactobacillus casei, Lactobacillus paracasei ssp. paracasei, Lactobacillus plantarum, Lactobacillus reuteri, Lactobacillus rhamnosus, Lactobacillus salivarius ssp. salivarius, Lactobacillus suntoryeus ssp. HY780I, Lactococcus lactis, Propionibacterium freudenreichii ssp. shermanii, Saccharomyces boulardii, and Streptococcus salivarius ssp. thermophilus.

\section{Data extraction and quality assessment}

Information regarding characteristics, outcome assessment and reporting, and adverse study effects was abstracted for each study that was selected for review. The Jadad scale was employed to assess the methodological quality of the retrieved studies (14). This scale adds single scoring points when the study is described as randomized, when it is described as double blind, and when a description of withdrawals and dropouts is present. A description and adequate method of randomization or a description and adequate method of blinding each result in the addition of 2 points. A score of 4 or more points indicated a well-designed study.

\section{Statistical analysis}

Sample size and mean and standard deviation (SD) data for each group [treatment group (TG) and control group (CG)] were collected as summary statistics at the end of the treatment period. Data were combined using standardized mean differences (SMD) because different scales were used in the studies to evaluate the effect of probiotics on each symptom. Heterogeneity between studies was assessed using Cochran's Q test, and the $\mathrm{I}^{2}$ index was used to quantify the amount of heterogeneity, with a value greater than $50 \%$ indicating substantial heterogeneity $(15,16)$. The study-specific SMDs were weighted by the inverse of their variance to compute a pooled mean difference and its $95 \%$ confidence interval (CI) using a random-effects model in cases of heterogeneity (17); otherwise, fixed-effects models were used. All analyses were performed using the Stata (18) 12.0 software (Stata Corporation, College Station, TX, USA).

\section{RESULTS}

The literature searches yielded 252 publications, 37 of which were considered potentially relevant and were retrieved (4-6,19-52). Of these, 24 studies were judged to meet the inclusion criteria (Fig. 1) (4-6,19-39). Table I contains a list of excluded studies and the reason for exclusion (40-52).

Data for the meta-analysis were extracted from 10 studies $(19,20,25,29,31,32,34,36,37,39)$. The other 14 studies were not suitable for meta-analysis. 


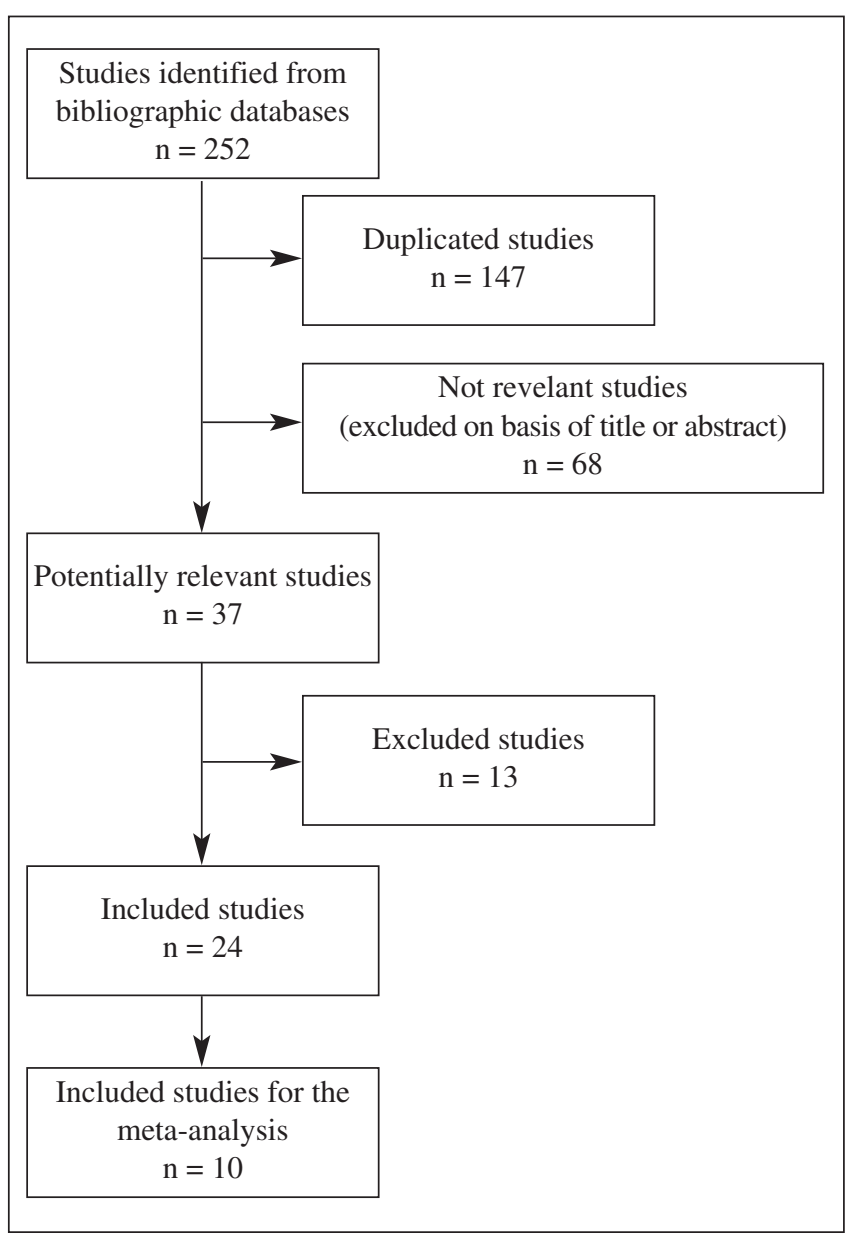

Fig. 1. Summary of the study selection and exclusion processes.

\section{Study quality}

The quality of the studies evaluated in this review was high, with only $6(25 \%)$ having a punctuation lower than 4 (Table II). Items where criteria for a quality indicator were not all fulfilled or could not be evaluated for the majority of studies were "description and adequate method of randomization" and "withdrawals and dropouts", with a total punctuation of 11/24 and 14/24 points, respectively.

From the 10 articles retrieved for the meta-analysis, 3 $(30 \%)$ had a punctuation lower than 4 (studies highlighted in italics in table II).

\section{Study characteristics}

The characteristics of the studies included in the review are summarized in table III. This table provides information regarding participants, interventions, and main outcomes. The treatment phase lasted between 4 and 8 weeks in most studies, with the exception of 3 that lasted 5 (5) and 6 months $(37,38)$.
Table I. Studies excluded from the review and the reason for exclusion

\begin{tabular}{ll}
\hline Reason for exclusion & Reference \\
\hline Other criteria than Rome criteria & Enck et al., 2009 (40) \\
for diagnosis/diagnostic criteria & Enck et al., 2008 (41) \\
not clearly stated & Moon et al., 2007 (43) \\
& Enck et al., 2007 (44) \\
& Niedzielin et al., 2001 (50) \\
& Gade et al., 1989 (51) \\
& Maupas et al., 1983 (52) \\
\hline
\end{tabular}

No comparison of the efficacy between groups

Kajander et al., 2007 (42)

\begin{tabular}{ll}
\hline Not a randomized controlled trial & Kajander et al., 2006 (47) \\
\hline Not statistical analysis of the results & Saggioro, 2004 (49) \\
\hline Congress abstract & Holowacz, 2007 (45) \\
& Simren, 2007 (46) \\
& Simren, 2006 (48)
\end{tabular}

\section{Adverse events}

The presence of adverse effects was mentioned in all but 6 studies $(6,19-21,32,37)$. Reported adverse effects were few and were not serious. Additionally, the number of adverse events was similar in the TG and CG.

\section{IBS symptoms}

The most common symptoms studied in the randomized controlled trials accepted for review were abdominal pain or discomfort, bloating or distension, stool frequency, stool consistency, flatulence, straining during stool evacuation, incomplete evacuation, fecal urgency, and QOL.

The meta-analysis results are shown in table IV. The results for each IBS symptom evaluated are described according to the presence of a specific probiotic species.

\section{Abdominal pain or discomfort}

All retrieved studies evaluated the effects of probiotics on pain (4-6,19-39). The meta-analysis revealed a significant effect of probiotics in improving pain scores in probiotics containing B. breve, B. longum, or L. acidophilus species $(25,29,31,32,34,36,37,39)$ and an almost significant effect for $S$. salivarius ssp. thermophilus species (25,29,31,32,34,36,39). B. animalis, B. infantis, L. casei, L. plantarum, L. bulgaricus, and S. boulardii species did not significantly improve pain $(19,20,25,31,34,36,39)$.

Significant pain alleviation was not found in 16 studies $(6,19,20,22-26,29,32,34,36-39)$, although a pain alleviation trend was found in 4 studies $(5,23,32,37)$. Both the TG and 
Table II. Methodological quality assessment of randomized trials (Jadad Scale)

\begin{tabular}{|c|c|c|c|c|c|c|}
\hline Reference & Randomization & $\begin{array}{l}\text { Description and } \\
\text { adequate method } \\
\text { of randomization }\end{array}$ & $\begin{array}{l}\text { Double } \\
\text { blinding }\end{array}$ & $\begin{array}{l}\text { Description and } \\
\text { adequate method } \\
\text { of randomization }\end{array}$ & $\begin{array}{l}\text { Withdrawals } \\
\text { and dropouts }\end{array}$ & $\begin{array}{l}\text { Total } \\
\text { score }\end{array}$ \\
\hline Kabir, 2011 (19) & Yes & No & Yes & Yes & No & 3 \\
\hline Choi, 2011 (20) & Yes & Yes & Yes & Yes & No & 4 \\
\hline Guglielmetti, 2011 (21) & Yes & Yes & Yes & Yes & Yes & 5 \\
\hline Hong, 2011 (22) & Yes & No & Yes & Yes & Yes & 4 \\
\hline Sondergaard, 2011 (23) & Yes & Yes & Yes & Yes & No & 4 \\
\hline Michail, 2011 (24) & Yes & Yes & Yes & Yes & No & 4 \\
\hline Simren, 2010 (25) & Yes & Yes & Yes & Yes & No & 4 \\
\hline Dolin, 2009 (26) & Yes & No & Yes & Yes & No & 3 \\
\hline Hun, 2009 (27) & Yes & No & Yes & No & No & 2 \\
\hline Kyoung, 2009 (28) & Yes & Yes & Yes & Yes & Yes & 5 \\
\hline Williams, 2009 (29) & Yes & No & Yes & Yes & Yes & 4 \\
\hline Agrawal, 2009 (30) & Yes & No & Yes & Yes & No & 3 \\
\hline Zeng, 2008 (31) & Yes & No & No & No & Yes & 2 \\
\hline Drouault-Holowacz, 2008 (32) & Yes & Yes & Yes & Yes & Yes & 5 \\
\hline Sínn, 2008 (33) & Yes & Yes & Yes & Yes & Yes & 5 \\
\hline Kajander, 2008 (5) & Yes & Yes & Yes & Yes & Yes & 5 \\
\hline Guyonnet, 2007 (34) & Yes & No & Yes & Yes & Yes & 4 \\
\hline Whorwell, 2006 (35) & Yes & No & Yes & Yes & Yes & 4 \\
\hline Kim, 2005 (36) & Yes & No & Yes & Yes & No & 2 \\
\hline Kajander, 2005 (37) & Yes & Yes & Yes & Yes & Yes & 5 \\
\hline Niv, 2005 (38) & Yes & No & Yes & Yes & Yes & 4 \\
\hline O’Mahony, 2005 (4) & Yes & Yes & Yes & Yes & No & 4 \\
\hline Kim, 2003 (39) & Yes & No & Yes & Yes & Yes & 4 \\
\hline Nobaek, 2000 (6) & Yes & No & Yes & Yes & Yes & 4 \\
\hline
\end{tabular}

Italics type indicates studies included in the meta-analysis

CG improved during the intervention in 5 studies that reported data analyzing individual pain improvement for each of the groups before and after the study $(6,24,25,29,34)$, with the exception of 1 study in which the TG improved but not the CG (24).

Probiotics significantly improved pain in 6 studies $(4,21,28,30,33,35), 2$ of which provided data of individual pain improvement for each of the groups before and after the study period. These 2 studies both showed improvement for the TG $(21,33)$ and 1 showed improvement for the CG (21). Whorwell et al. (35) found a statistically significant pain reduction in a subgroup of patients with constipation (C-IBS) compared to the CG.

Two studies only provided data of the improvement for each of the groups before and after the study period (27,31). Both showed a significant improvement in the TG and 1 showed a significant improvement in the CG (27).

\section{Abdominal bloating or distension}

Eighteen studies evaluated the effects of probiotics on distension (4,5,19-25,27,29-31,34-37,39). The meta-analy- sis revealed that probiotics significantly improved distension scores if they contained B. breve, B. infantis, L. casei, or L. plantarum species $(36,37,39)$. B. animalis, B. longum, L. acidophilus, S. boulardii, L. bulgaricus, or S. salivarius ssp. thermophilus species did not significantly affect distension $(19,20,25,29,31,34,36,39)$.

Distension was not significantly improved in 13 studies (4,19,20,22-25,29,30,34,36,37,39), although 5 studies, showed a trend toward improvement $(23,30,36,37,39)$. Of these 13 studies, 5 reported the data by analyzing individual distension improvement for each of the groups before and after the study $(24,25,29,34,39)$. Both the TG and CG improved during the intervention in these studies, with the exception of 2 studies in which the TG improved but not the CG $(24,39)$.

Probiotics significantly improved distension in 3 studies $(5,21,35)$. Whorwell et al. (35) found a trend of decreased distension in the subgroup of patients with diarrhea (DIBS) compared to the CG.

Two studies only provided data on the improvement for each of the groups before and after the study period $(27,31)$, both of which showed a significant improvement in the TG and $\mathrm{CG}$. 


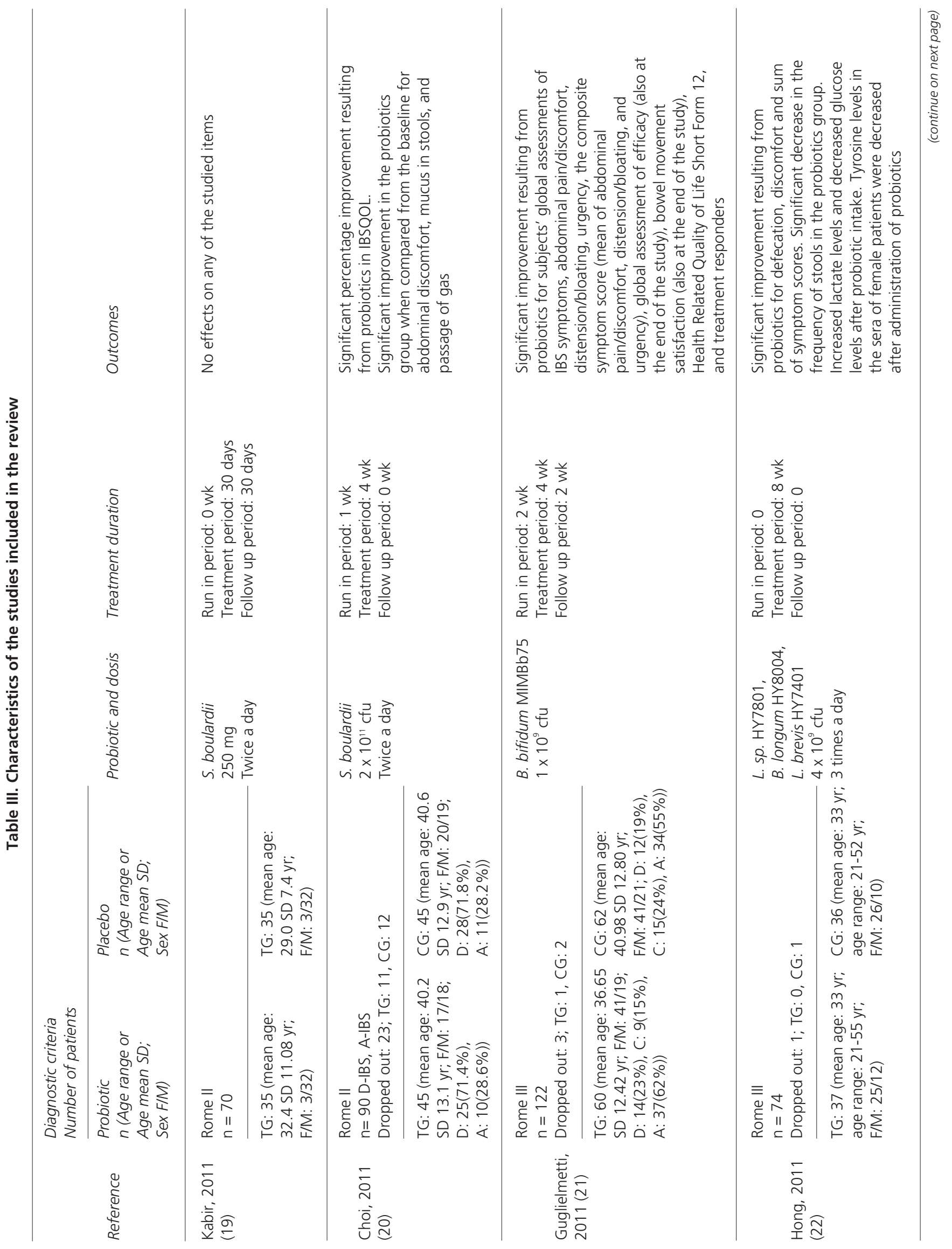


M. ORTIZ-LUCAS ET AL.

Rev EsP ENFerm Dig (Madrid)

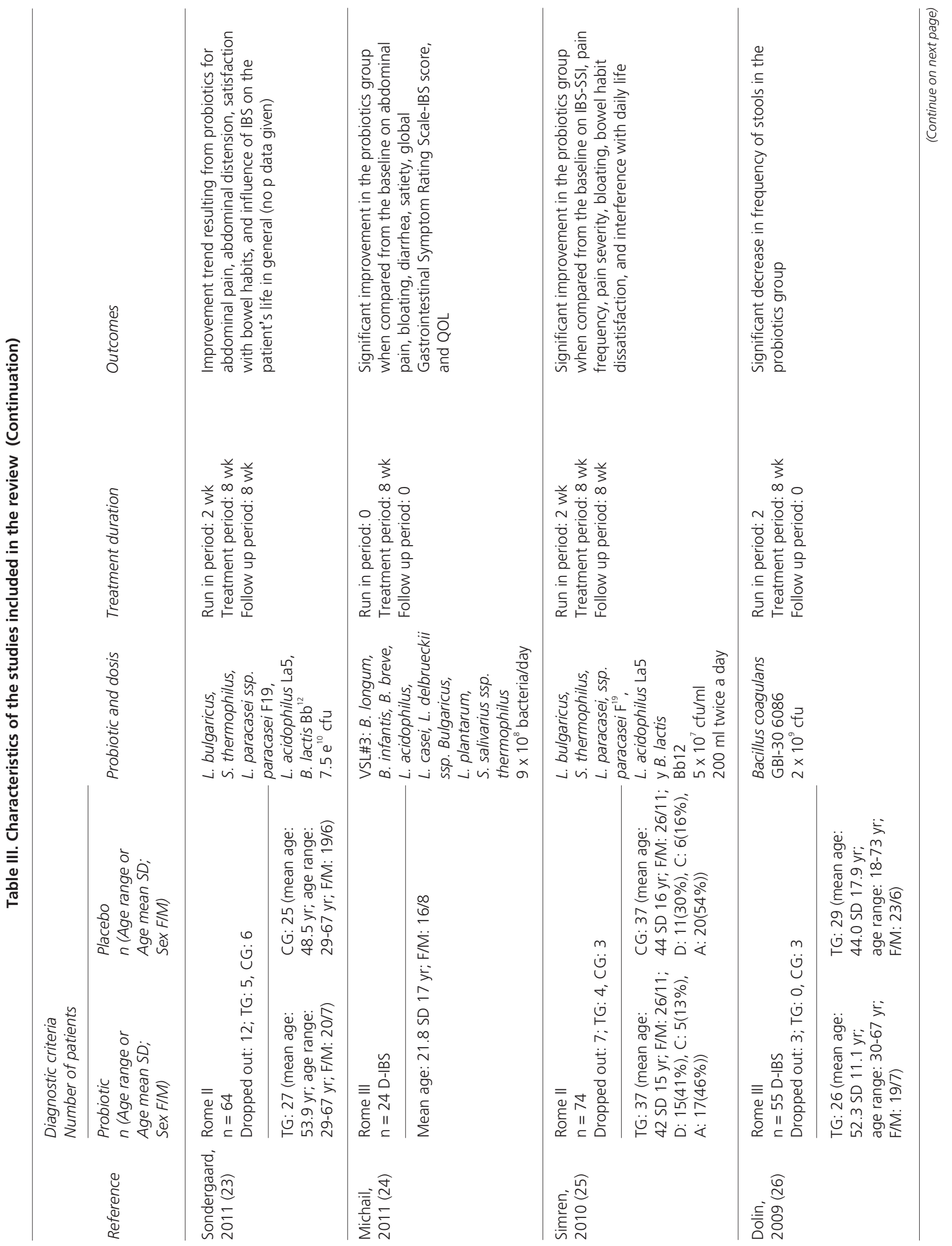

REv EsP ENFERM Dig 2013; 105 (1): 19-36 


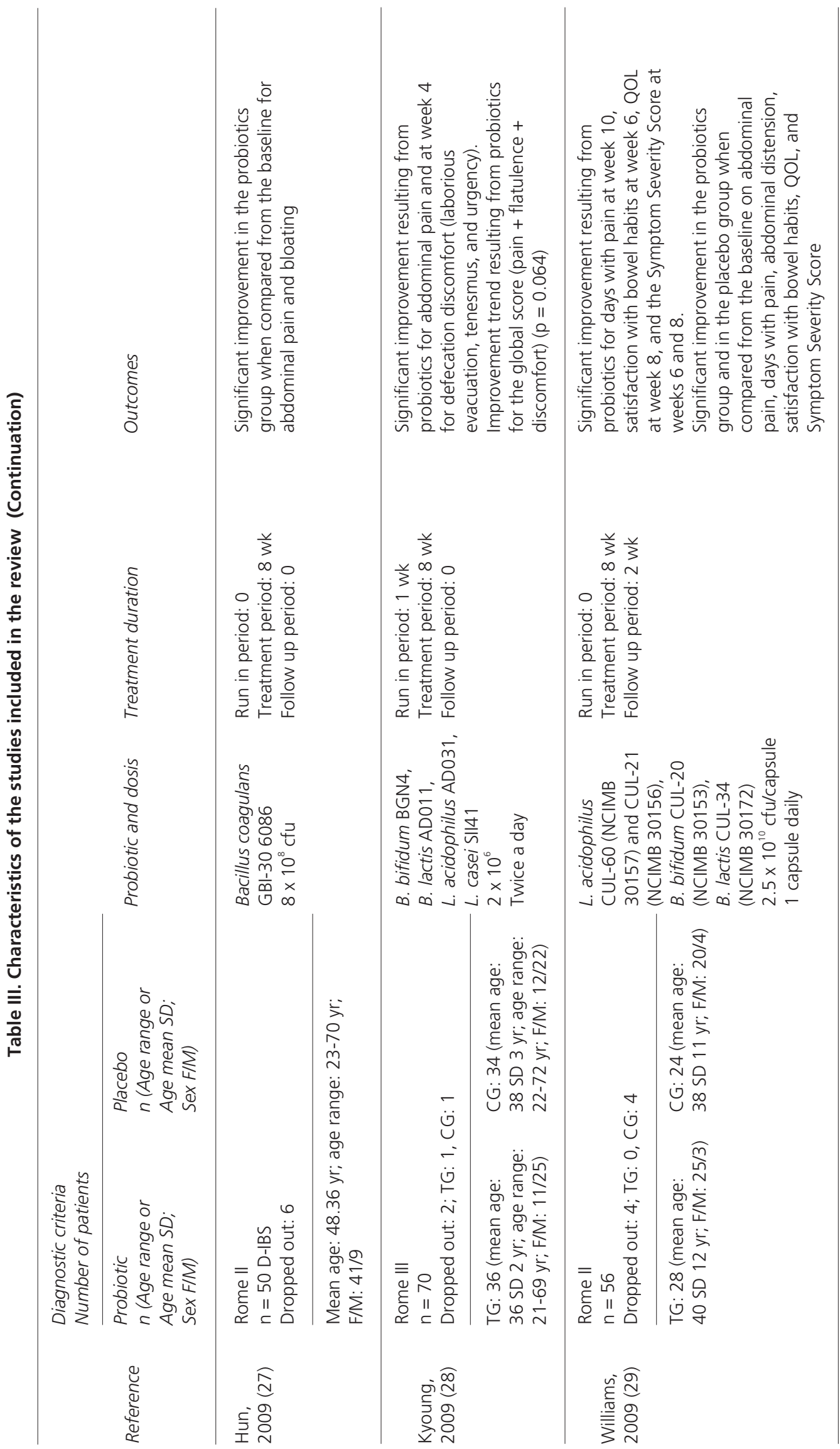

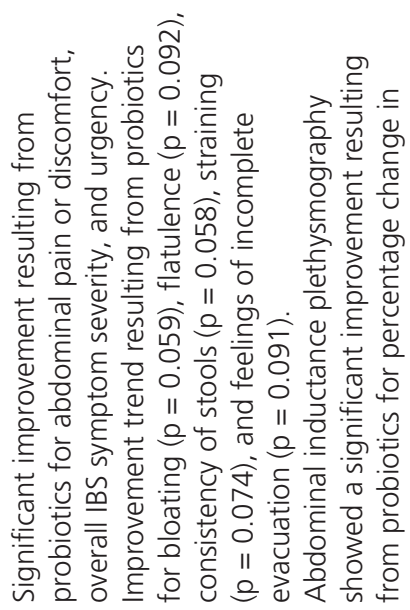

\section{$\stackrel{\substack{\pi \\ \frac{\pi}{0}}}{\stackrel{n}{0}}$ \\ $\sim \infty$ \\ $\circ \ddot{\overline{0}} \ddot{\circ}$

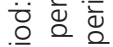

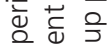

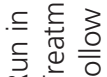 \\ × $上$ 웅}

응 $+\frac{0}{\frac{0}{0}}$

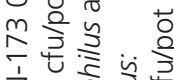

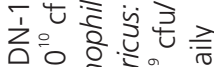

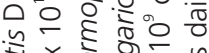

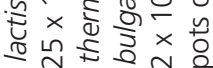

min

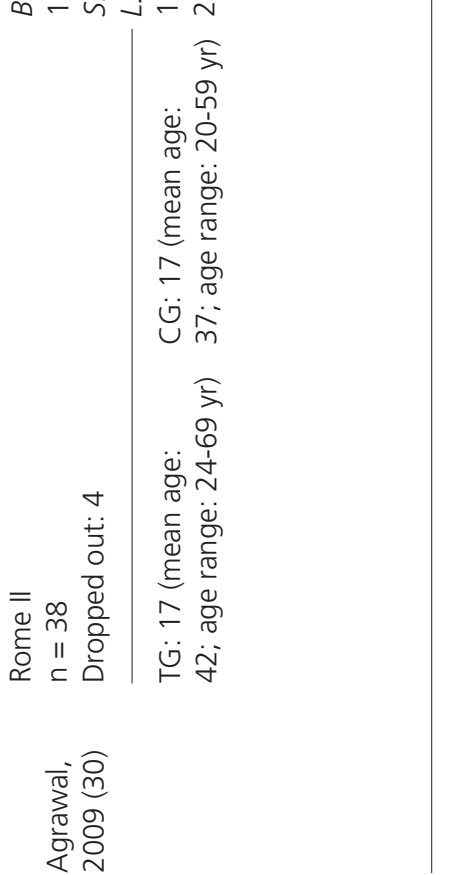




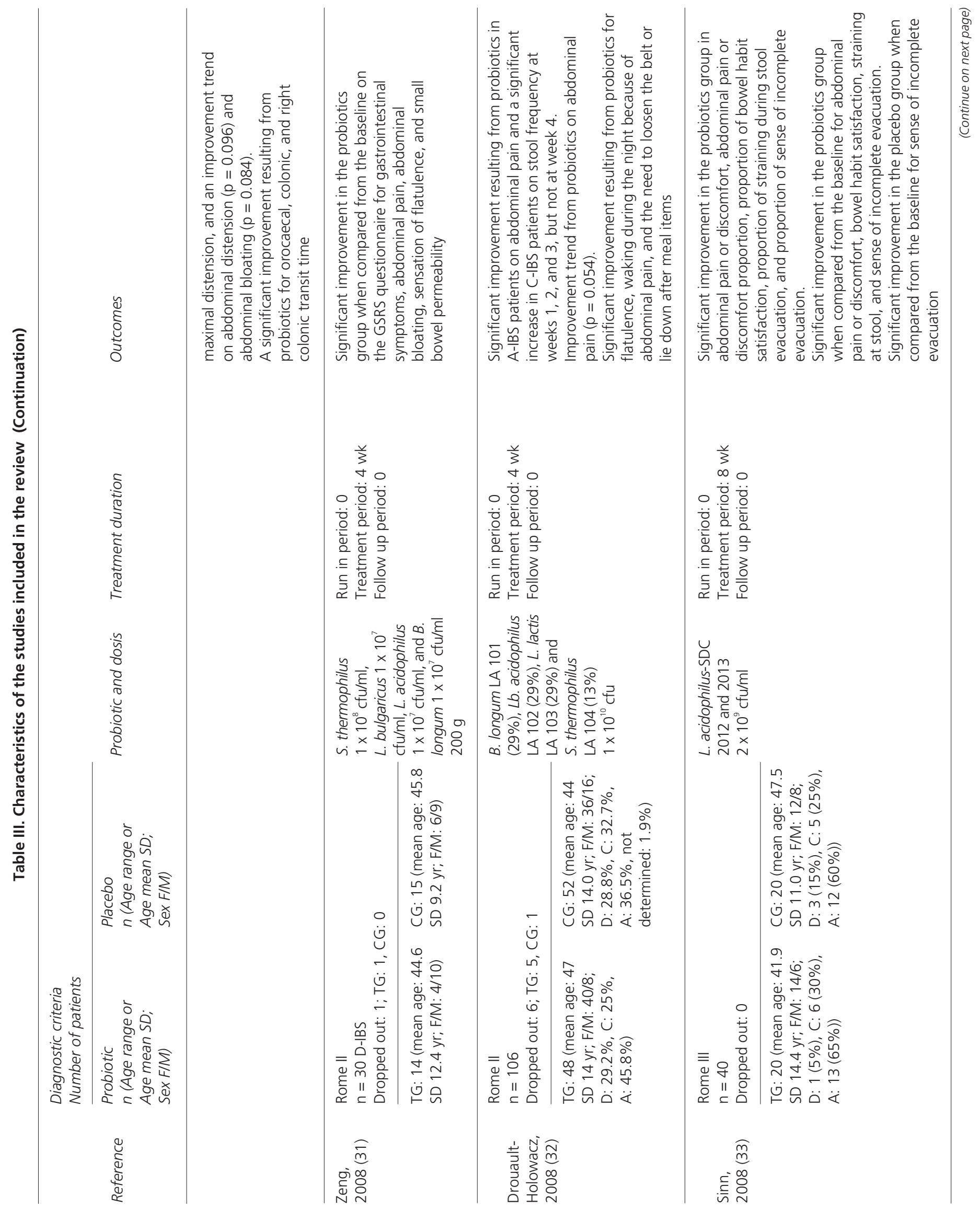




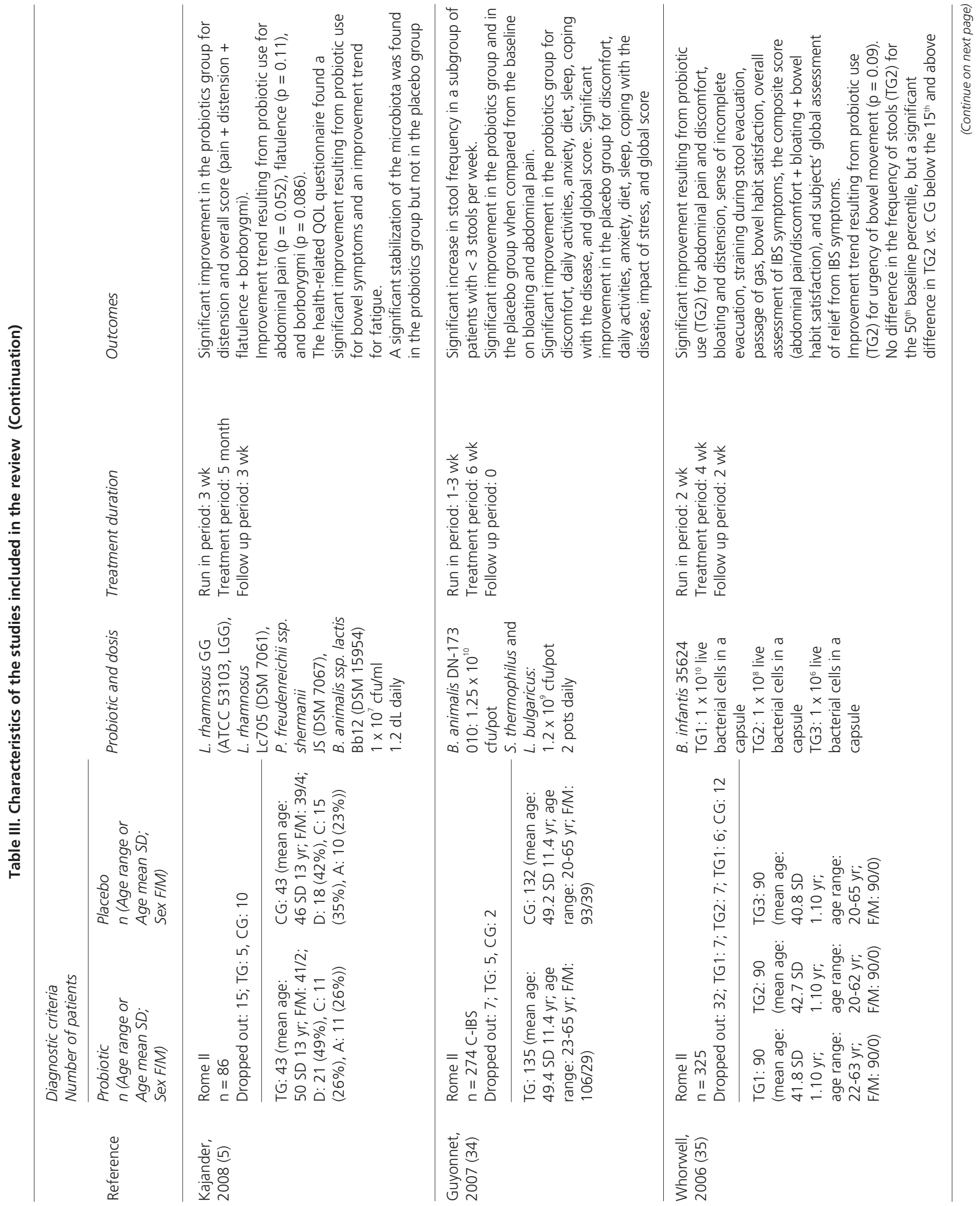




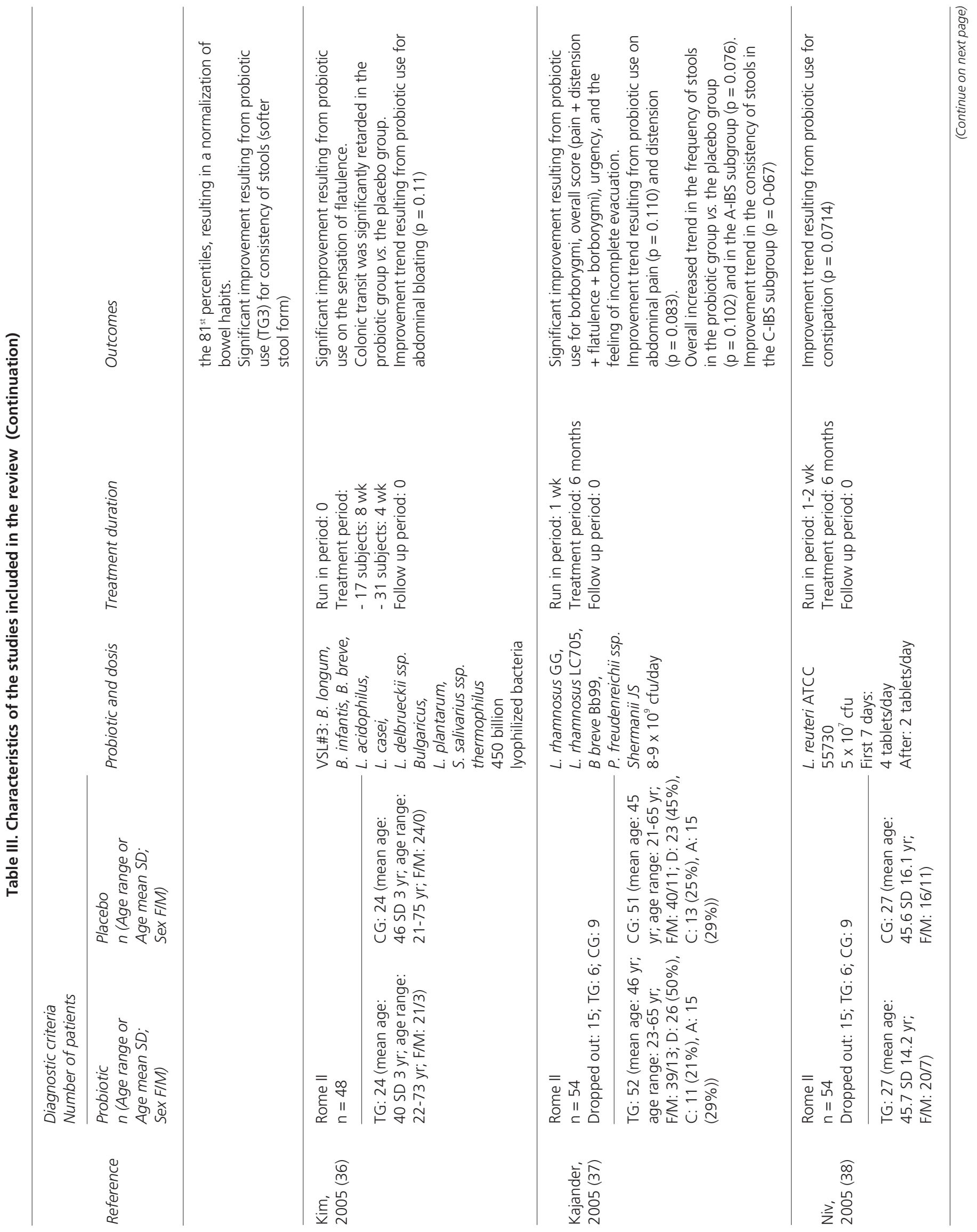




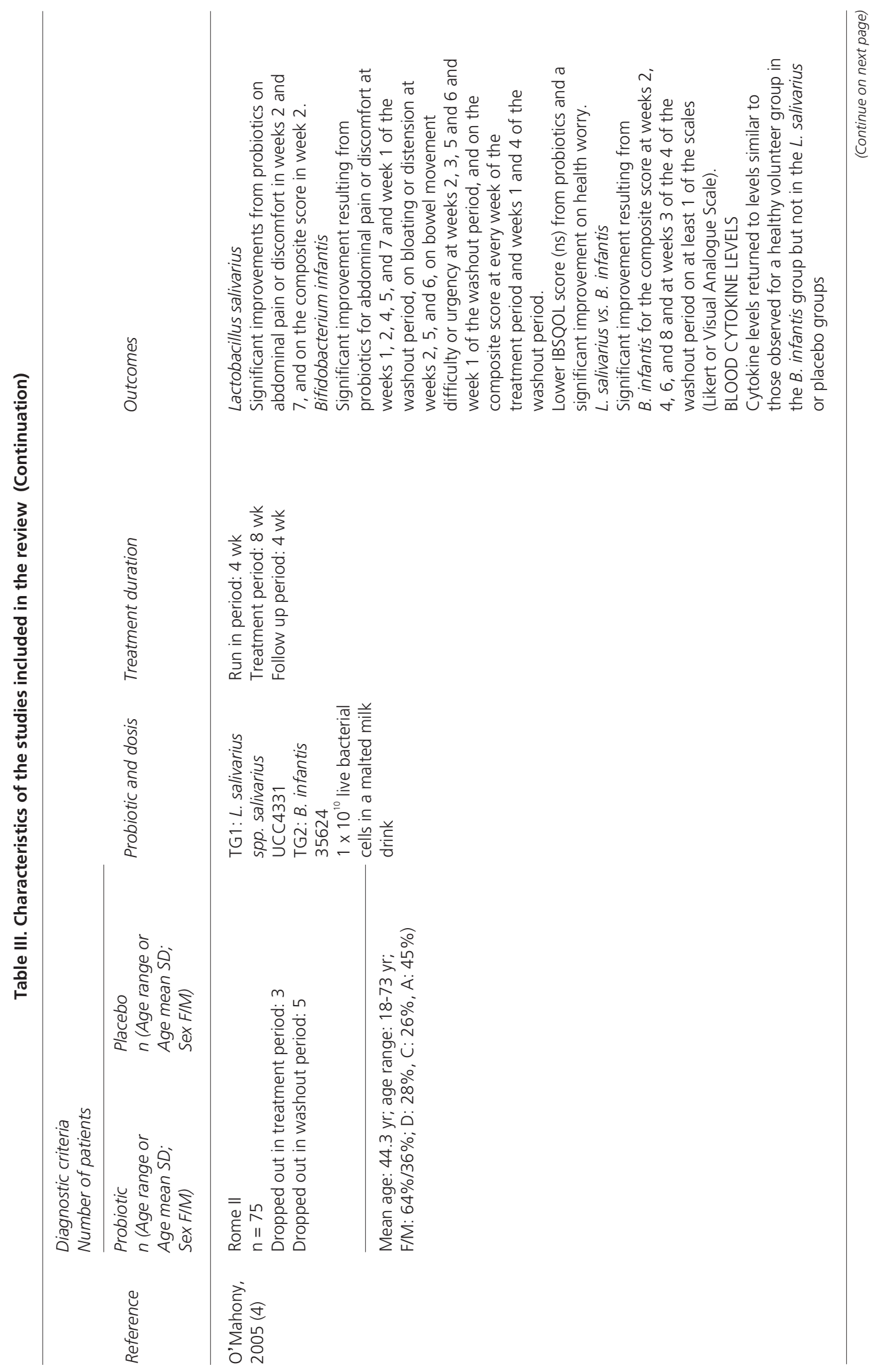




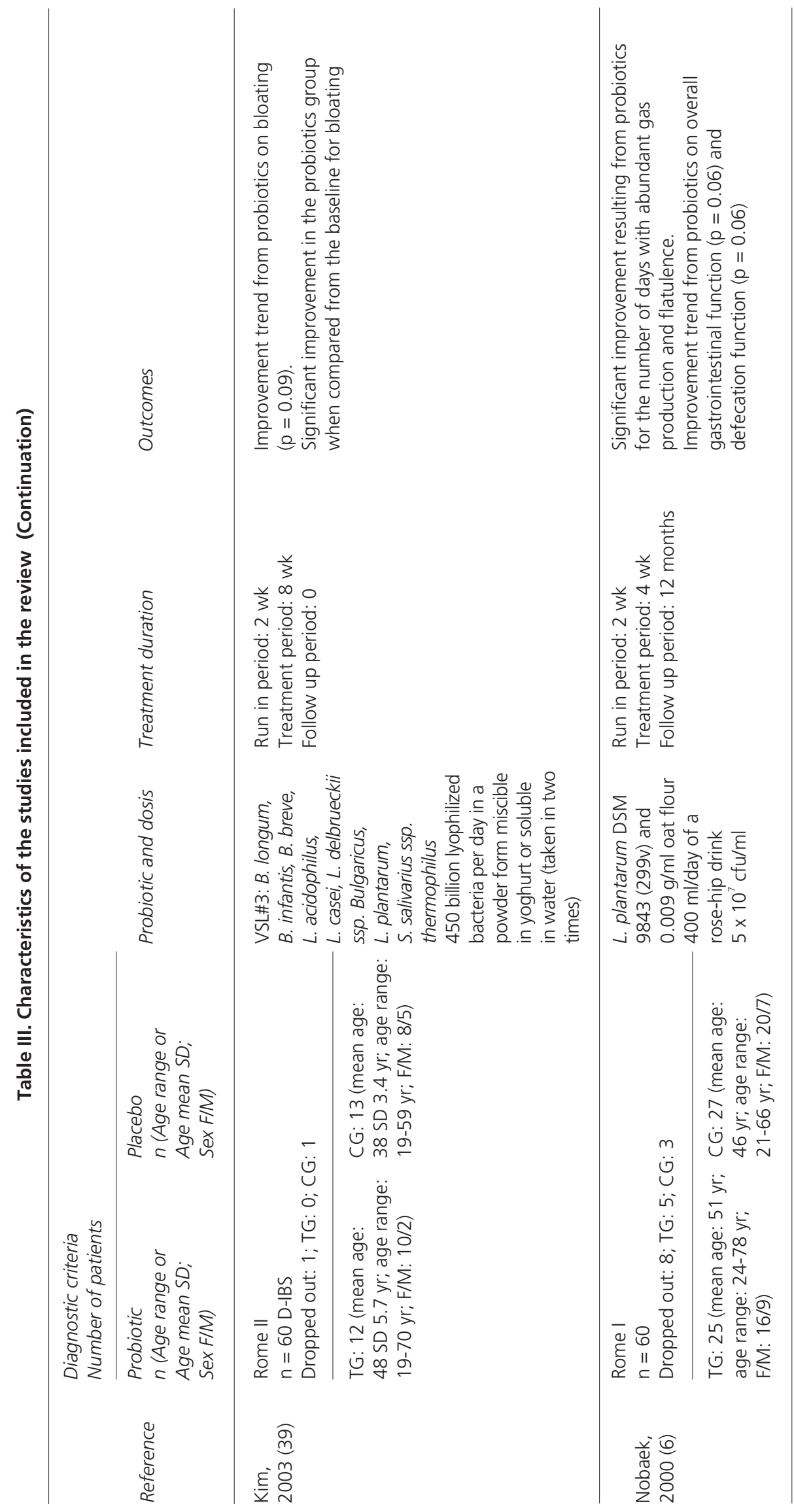


Table IV. Meta-analysis of the efficacy of probiotics species for treating IBS patients. The results refer to the presence of any probiotic species for treating each IBS symptom

\begin{tabular}{llll}
\hline Outcome & $n$ & No. of patients & $\begin{array}{c}\text { Overall estimates } \\
\text { SMD (95\% CI) }\end{array}$ \\
\hline
\end{tabular}

\section{PAIN}

B. Animalis $(25,29,34)$

B. Breve $(36,37,39)$

$3 \quad 393$

$3 \quad 154$

B. Casei - L. Plantarum $(36,39)$

154

73

B. Longum $(31,32,34,39)$

L. Acidophilus $(25,29,31,32,36,39)$

L. Bulgaricus $(25,31,34,36,39)$

S. Boulardii $(19,20)$

S. Salivarius ssp. Thermophilus

$(25,31,32,34,36,39)$

\section{DISTENSION}

B. Animalis $(25,29,34)$

B. Breve $(36,37,39)$

B. Infantis - L. Casei - L. Plantarum $(36,39)$

$\begin{array}{lr}2 & 73 \\ 4 & 202\end{array}$

$6 \quad 328$

5443

$2 \quad 137$

$6 \quad 543$

443
137
543

$0.0(0.1 ; 2 ; 0.943)$

$-0.28(-0.56 ; 0.00)$

$-0.05(-0.24 ; 0.15)$

$-0.34(-0.66 ;-0.02)$

$-0.31(-0.77 ; 0.15)$

$-0.48(-0.91 ;-0.06)$

$-0.31(-0.61 ;-0.01)$

$-0.31(-0.67 ; 0.05)$
$0.0(0.1 ; 2 ; 0.943)$

$0.0(0.1 ; 1 ; 0.763)$

$49.5(5.9 ; 3 ; 0.115)$

$42.3(8.7 ; 5 ; 0.123)$

$59.4(9.6 ; 4 ; 0.043)$

$0.0(0.2 ; 1 ; 0.652)$

$50.5(10.1 ; 5 ; 0.072)$

B. Longum $(31,36,39)$

L. Acidophilus $(25,29,31,36,39)$

S. Boulardii $(19,20)$

L. Bulgaricus - S. Salivarius ssp.

Thermophilus $(25,31,32,34,39)$

STOOL FREQUENCY

B. Breve $(36,37,39)$

B. Infantis - B. Longum - L. Acidophilus -

$3 \quad 154$

\section{3}

154

73

102

228

137

443
$0.00(-0.20 ; 0.20)$

$-0.45(-0.77 ;-0.13)$

$-0.53(-1.00 ;-0.06)$

$-0.19(-0.90 ; 0.53)$

$-0.17(-0.51 ; 0.18)$

$-0.06(-0.67 ; 0.55)$

$-0.08(-0.39 ; 0.24)$
$0.0(1.0 ; 2 ; 0.612)$

$0.0(0.3 ; 2 ; 0.858)$

$0.0(0.1 ; 1 ; 0.749)$

$67.6(6.2 ; 2 ; 0.046)$

$38.2(6.5 ; 4 ; 0.167)$

$69.1(3.2 ; 1 ; 0.072)$

$49.7(2.0 ; 1 ; 0.159)$

L. Bulgaricus - L. Casei - L. Plantarum -

S. Salivarius ssp. Thermophilus $(36,39)$

\section{STOOL CONSISTENCY}

$B$. Breve - B. Infantis - B. Longum -

2

73

$-0.04(-0.50 ; 0.42)$

$0.0(1.0 ; 1 ; 0.326)$

Acidophilus - L. Bulgaricus

L. Casei - L. Plantarum - S. Salivarius ssp.

Thermophilus $(36,39)$

\section{FLATULENCE}

B. Breve $(36,37,39)$

B. Infantis - L. Casei - L. Plantarum $(36,39)$

B. Longum - L. Acidophilus -

$154 \quad 0.13(-0.49 ; 0.74)$

$-0.27(-0.73 ; 0.19)$

$47.2(7.6 ; 4 ; 0.108)$

2

73

$0.0(0.0 ; 1 ; 0.966)$

L. Bulgaricus - S. Salivarius ssp.

Thermophilus $(31,36,39)$

STRAINING

B. Breve - B. Infantis - B. Longum -

2

73

$0.45(-0.16 ; 1.06)$

$36.7(1.6 ; 1 ; 0.209)$

L. Acidophilus - L. Bulgaricus - L. Casei -

L. Plantarum - S. Salivarius ssp.

Thermophilus $(36,39)$

URGENCY

B. Breve - B. Infantis - B. Longum -

2

154

73

$\begin{array}{lc}2 & 73 \\ 3 & 102\end{array}$

102

$-0.42(-0.75 ;-0.10)$
$-0.60(-1.07 ;-0.13)$
$-0.61(-1.01 ;-0.21)$

$0.0(1.9 ; 2 ; 0.389)$

$0.0(0.9 ; 1 ; 0.332)$

$0.0(1.0 ; 2 ; 0.621)$

L. Acidophilus - L. Bulgaricus - L. Casei -

L. Plantarum - S. Salivarius ssp.

Thermophilus $(36,39)$

SMD: standardized mean differences; Cl: confidence interval; I2: heterogeneity statistic; Q: Cochran s Q test; df: degrees of freedom; p: p-value. Italics indicates significance. 


\section{Stool frequency}

Sixteen studies evaluated the effects of probiotics on stool frequency $(4,6,19-22,26,28,30,32-37,39)$. Probiotics containing B. breve, B. infantis, B. longum, L. acidophilus, L. bulgaricus, L. casei, L. plantarum, or S. salivarius ssp. thermophilus species $(36,37,39)$ did not improve frequency scores according to the meta-analysis.

Only 2 of 16 studies showed a significant decrease in the stool frequency $(22,26)$. One study showed an increased trend in the stool frequency, which was also shown in the alternators IBS subgroup, but this tendency was not found in the D-IBS or C-IBS subgroup (37). Drouault-Holowacz et al. (32) found a significant increase in the stool frequency in a subgroup of patients with C-IBS at weeks 1, 2, and 3, but not at week 4, of probiotic consumption. Guyonnet et al. (34) found a significant increase in a subgroup of patients with less than 3 stools per week. Whorwell et al. (35) found a normalization of bowel habits in patients below the $15^{\text {th }}$ and above the $81^{\text {th }}$ stool frequency percentiles.

\section{Stool consistency}

Sixteen studies evaluated the effects of probiotics on stool consistency (4-6,19,20,22,26,28,30,32-37,39). Probiotics containing B. breve, B. infantis, B. longum, L. acidophilus, $L$. bulgaricus, L. casei, L. plantarum, or S. salivarius ssp. thermophilus species $(36,39)$ did not significantly improve consistency scores according to the meta-analysis.

Although none of these studies showed a significant improvement on stool consistency, improvement trends were found by Agrawal et al. (30) and Whorwell et al. (35) in a group treated with $1 \times 10^{6}$ live bacterial cells. Nobaek et al. (6) found a significant decrease in the number of days with rather loose to very loose stools and a significant increase in the number of days with normal stools, but not in the number of days with rather hard to very hard stools.

\section{Flatulence}

Ten studies evaluated the effects of probiotics on flatulence $(5,6,26,28,30-32,36,37,39)$. The meta-analysis found that all probiotic species studied: $B$. breve, B. infantis, $L$. casei, L. plantarum, B. longum, L. acidophilus, L. bulgaricus, and S. salivarius ssp. thermophilus $(31,36,37,39)$ significantly improved flatulence scores.

Significant improvements in flatulence were not found in 6 studies $(5,26,28,30,37,39)$, although $2(5,30)$ showed a trend of improvement. Kajander et al. (37) found a significant improvement in flatulence in those patients in whom the symptom score had decreased.

Flatulence was significantly improved by probiotics in 3 studies $(6,32,36)$. Individual flatulence improvement for the TG and CG was found before and after the study period in 1 study (6). Improvement in the TG but not the CG before and after the study period was found in another study (31).

\section{Straining during stool evacuation}

Seven studies evaluated the effects of probiotics on straining (20,30,33,35-37,39). Probiotics containing $B$. breve, B. infantis, B. longum, L. acidophilus, L. bulgaricus, L. casei, L. plantarum, or S. salivarius ssp. thermophilus species $(36,39)$ did not significantly improve straining scores according to the meta-analysis.

Straining was not alleviated in 5 studies $(20,30,36,37,39)$, but a trend toward improvement was found in 1 of these studies (30).

Probiotics significantly improved straining in the TG and a subgroup of patients with D-IBS compared to the CG in 1 study (35). Sinn et al. (33) found a significant decrease in straining when considering the percentage reduction of the symptom score and found an improvement in the TG, but not in the $\mathrm{CG}$, when comparing data before and after the study period.

\section{Sense of incomplete evacuation}

Seven studies evaluated the effects of probiotics on the sense of incomplete evacuation (20,21,30,33,35-37), 3 of which did not show a significant improvement $(20,21,36)$. One of these studies (20) showed an improvement in the TG, but not in the CG, when comparing data before and after the study.

Probiotics significantly improved the sense of incomplete evacuation in 4 studies $(30,33,35,37)$. Sinn et al. (33) found a significant improvement when considering the percentage reduction of the symptom score and found a significant improvement in both the TG and CG when comparing data before and after the study period. Whorwell et al. (35) found an improvement in the subgroup of patients with D-IBS compared to the $\mathrm{CG}$.

\section{Fecal urgency}

Nine studies evaluated the effects of probiotics on fecal urgency $(4,20,21,26,30,35-37,39)$. Probiotics containing B. breve, B. infantis, B. longum, L. acidophilus, L. bulgaricus, L. casei, L. plantarum, or S. salivarius ssp. thermophilus $(36,39)$ did not significantly improve fecal urgency according to the meta-analysis.

Fecal urgency was not significantly improved in 6 studies $(4,20,26,35,36,39)$. One of these studies (35) found a trend for improved urgency and another (39) found an improvement in the TG, but not in the CG, when comparing data before and after the study period.

Probiotics significantly improved urgency in 4 studies (4,21,30,37). O'Mahonny et al. (4) found this improvement 
in the group treated with $B$. infantis at weeks $2,3,5$, and 6 and at week 1 of the wash out period. This improvement was not observed in the group treated with L. salivarius ssp. salivarius. Whorwell et al. (35) found a trend of decreased fecal urgency in the subgroup of patients with D-IBS compared to the CG.

\section{IBS QOL}

Twelve studies evaluated the effects of probiotics on QOL (4,5,20,21,24-26,28,29,32,35,38), 7 of which did not find a significant improvement $(24-26,28,32,35,38)$. One of these studies (24) found an improvement in the TG, but not in the $\mathrm{CG}$, when comparing data before and after the study period.

Probiotics significantly improved QOL in 5 studies $(4,5,20,21,29)$. Choi et al. (20) found a significant improvement in the percentage reduction of the symptom score and Williams et al. (29) found an improvement in the TG and CG when comparing data before and after the study period. Kajander et al. (5) showed a significant improvement in "bowel symptoms", a trend for improved "fatigue", but no effects on "activity limitations" and "emotional function" items. O’Mahonny et al. (4) found lower IBS-QOL scores for L. salivarius ssp. salivarius and B. infantis for most domains, but they only showed significance for "health worry" in the B. infantis group and a trend of improved "dysphoria" in the L. salivarius ssp. salivarius group.

\section{DISCUSSION}

This review and meta-analysis provides additional evidence for the beneficial effect of probiotics in IBS treatment. Several authors found altered microbiota in IBS patients (53-57). Intestinal bacteria may play a significant role in inducing IBS because a change in the microbiota can lead to an activation of the immune system, which could explain symptom generation and the effects on the central nervous system (58-64). Probiotic intake may preserve the fecal microbiota (5), normalize the cytokine blood levels (4), improve the intestinal transit time (30), decrease the small intestine permeability (31), and alter the fermentation pattern reducing the small intestinal bacterial overgrowth (65) in these patients, but further research is required to confirm these results.

Although positive effects of probiotics were found in this review and meta-analysis, many studies have not found a significant effect. This may result from the significant improvements found in the TG and in $\mathrm{CG}$ when comparing data from the baseline in many of these studies, which is consistent with the placebo effect and with the fluctuating symptoms found in these patients (66-68).

The differences in these study results could also be attributable to the characteristics of the disease. Rome criteria provide a useful tool to diagnose IBS patients, but the subjectivity of quantifying IBS symptoms is a limitation when studying the efficacy of a therapy (68-70). Additionally, these differences can be due to variations in study design, duration, IBS population, and probiotic dose and species. These factors make it difficult to compare the results of these studies.

Although other published reviews and meta-analyses have studied the effects of probiotics in IBS patients (712,71 ), our study evaluated the efficacy of probiotics on a wide variety of IBS symptoms. This allowed us to determine whether a specific probiotic species is beneficial for treating individual IBS symptoms. To our knowledge, only 1 other meta-analysis studied the effects of individual species on IBS treatment. The authors found no impact on symptoms in patients treated with Lactobacilli but found a significant improvement when patients were treated with probiotic combinations. They suggested that Bifidobacteria were the active ingredients in probiotic combinations because they found a non-significant improvement trend from Bifidobacteria for IBS symptoms (12).

The results of this meta-analysis corroborate the positive effects found for the treatment of pain in IBS patients in other meta-analyses $(7,10,12)$. However, Hoveyda et al. found this improvement when considering dichotomous data but not continuous data (7) and McFarland et al. only considered dichotomous data in their analysis (10). Other reviews state that probiotics have a positive effect on abdominal pain, suggesting that this effect is species specific $(11,71)$.

The different results found in other meta-analyses concerning the efficacy of probiotics in improving distension could be explained by the presence or absence of different probiotic species in the mixture, as shown in this meta-analysis $(7,12)$. This is corroborated by other reviews $(11,71)$.

We found that the presence of any probiotic species had a positive effect on flatulence. Other meta-analysis found a positive effect when considering any probiotic mixture $(7,12)$. However, Hoveyda et al. (7) noted this improvement when considering dichotomous data but not when considering continuous data.

The effects of probiotics on the frequency or consistency of stools should be studied with caution because these factors vary in IBS patients. Some of the retrieved studies found that probiotics had a positive effect on the frequency of stools in D-IBS patients $(24,26,35)$, while others did not $(37,39)$. Similarly, positive $(32,34,35)$ or negative $(37)$ results were found for C-IBS patients. No effects on the consistency of stools have been shown in D-IBS and CIBS subgroups $(6,26,34,37,39)$, with the exception of Nobaek et al. (6) (see results) and a trend of improvement in C-IBS patients (37). Further analyses should be performed on the stool profiles of these patients.

In addition to the previously discussed factors, future studies should include aspects such as focusing probiotics treatment on patients with a predominance of gastrointestinal symptoms, obtaining the microbiological profile of patients (55), or considering the psychological profile of patients (72).

Although the absence of adverse effects is an additional advantage of probiotic therapy, clinicians should consider 
the global state of the patient before prescribing them $(13,60,72)$.

A study published after our meta-analysis found that a probiotic mixture containing L. acidophilus (KCTC 11906BP), L. plantarum (KCTC 11867BP), L. rhamnosus (KCTC $11868 B P), B$. breve (KCTC 11858BP), Bifidobacterium lactis (KCTC 11903BP), B. longum (KCTC 11860BP), and Streptococcus thermophilus (KCTC 11870BP) did not have a significant effect on abdominal pain or discomfort, distension, stool frequency, urgency, or QOL in D-IBS patients. A significant improvement in stool consistency was seen in the probiotic group (73).

This study has several limitations. Some of the metaanalyses included a small number of randomized controlled trials because many studies did not provide adequate data for performing a meta-analysis. Furthermore, because most studies investigated the effect of a probiotic mixture, we could not carry out our analysis for specific probiotic species and/or mixtures. Instead, the meta-analysis was performed according to the presence of a specific probiotic species; this can provide an estimate of the influence of each species in alleviating individual IBS symptoms. Additionally, the inclusion of many symptoms in the analysis can provide benefits that are more specific for the treatment of individual patients. Another strength of this study is that the meta-analysis was performed with continuous rather than dichotomous data.

These results may enable development of individualized probiotic mixtures for each patient according to the predominant symptoms in the not-so-distant future. This is particularly true in IBS subtypes with a predominance of abdominal pain or discomfort and/or declined QOL, or when there is a predominance of abdominal distension or severe fecal urgency. We doubt that a standard probiotic mixture can improve any IBS symptom profile. Therefore, a standard IBS therapy that can be administered to every patient may not be possible.

In conclusion, evidence suggests that probiotics are an effective treatment option for IBS patients and that the effects of probiotics on each IBS symptom are likely species-specific. Future research should focus more specifically on species, combinations, dose, duration, IBS subtypes, and IBS individual symptoms, while employing standardized measurement tools. Although probiotics are a safe therapy, clinicians should consider other concomitant pathologies when prescribing them to their patients.

Our Research Group in Functional Digestive Disorders and Psychoimmunology, which is within the framework of the Biomedical Research Map of the Aragon Institute of Health Sciences in Spain, is convinced that the key factors in IBS are the immune system and intestinal microbiota after a detailed review of the scientific evidence concerning IBS. Therefore, we think that IBS treatment should focus on both of these factors influencing intestinal dysbiosis by considering the effects of different probiotic species on the symptomatology of individual patients.
Finally, we anticipate that a better design and combination of probiotics will soon be available for the treatment of IBS and other pathologies involving intestinal and general immunity.

\section{REFERENCES}

1. Enck P, Junne F, Klosterhalfen S, Zipfel S, Martens U. Therapy options in irritable bowel syndrome. Eur J Gastroenterol Hepatol 2010;22: 1402-11.

2. Ortiz Lucas M, Saz Peiró P, Sebastián Domingo JJ. Irritable bowel syndrome immune hypothesis. Part one: The role of lymphocytes and mast cells. Rev Esp Enferm Dig 2010;102:637-47.

3. Ortiz Lucas M, Saz Peiró P, Sebastián Domingo JJ. Irritable bowel syndrome immune hypothesis. Part two: The role of cytokines. Rev Esp Enferm Dig 2010;102:711-7.

4. O’Mahony L, McCarthy J, Kelly P, Hurley G, Luo F, Chen K, et al. Lactobacillus and bifidobacterium in irritable bowel syndrome: Symptom responses and relationship to cytokine profiles. Gastroenterology 2005; 128:541-51.

5. Kajander K, Myllyluoma E, Rajili-Stojanovi M, Kyrönpalo S, Rasmussen M, Järvenpää S, et al. Clinical trial: Multispecies probiotic supplementation alleviates the symptoms of irritable bowel syndrome and stabilizes intestinal microbiota. Aliment Pharmacol Ther 2008;27:48-57.

6. Nobaek S, Johansson ML, Molin G, Ahrné S, Jeppsson B. Alteration of intestinal microflora is associated with reduction in abdominal bloating and pain in patients with irritable bowel syndrome. Am J Gastroenterol 2000;95:1231-8.

7. Hoveyda N, Heneghan C, Mahtani KR, Perera R, Roberts N, Glasziou P. A systematic review and meta-analysis: Probiotics in the treatment of irritable bowel syndrome. BMC Gastroenterol 2009;9:15.

8. Wilhelm SM, Brubaker CM, Varcak EA, Kale-Pradhan PB. Effectiveness of probiotics in the treatment of irritable bowel syndrome. Pharmacotherapy 2008;28:496-505.

9. Nikfar S, Rahimi R, Rahimi F, Derakhshani S, Abdollahi M. Efficacy of probiotics in irritable bowel syndrome: A meta-analysis of randomized, controlled trials. Dis Colon Rectum 2008;51:1775-80.

10. McFarland LV, Dublin S. Meta-analysis of probiotics for the treatment of irritable bowel syndrome. World J Gastroenterol 2008;14:2650-61.

11. Brenner DM, Moeller MJ, Chey WD, Schoenfeld PS. The utility of probiotics in the treatment of irritable bowel syndrome: A systematic review. Am J Gastroenterol 2009;104:1033-49.

12. Moayyedi P, Ford AC, Talley NJ, Cremonini F, Foxx-Orenstein A, Brandt L, et al. The efficacy of probiotics in the therapy of irritable bowel syndrome: a systematic review. Gut 2010;59:325-32.

13. Rowland I, Capurso L, Collins K, Cummings J, Delzenne N, Goulet O, et al. Current level of consensus on probiotic science -report of an expert meeting-London, 23 November 2009. Gut Microbes 2010;1:436-9.

14. Jadad AR, Moore RA, Carroll D, Jenkinson C, Reynolds JM, Gavaghan DJ, et al. Assessing the quality of reports of randomized clinical trials: Is blinding necessary? Control Clin Trials 1996;17:1-12.

15. Higgins JP, Thompson SG. Quantifying heterogeneity in a meta-analysis. Stat Med 2002;21:1539-58.

16. Higgins JP, Thompson SG, Deeks JJ, Altman DG. Measuring inconsistency in meta-analyses. BMJ 2003;327:557-60.

17. DerSimonian R, Laird N. Meta-analysis in clinical trials. Control Clin Trials 1986;7:177-88.

18. Harris RJ, Bradburn MJ, Deeks JJ, Harbord RM, Altman DG, Sterne JAC. Metan: Fixed- and random-effects meta-analysis. Stata Journal 2009;8:3-28.

19. Kabir MA, Ishaque SM, Ali MS, Mahmuduzzaman M, Hasan M. Role of Saccharomyces Boulardii in diarrhea predominant irritable bowel syndrome. Mymensingh Med J 2011;20:397-401.

20. Choi CH, Jo SY, Park HJ, Chang SK, Byeon JS, Myung SJ. A randomized, double-blind, placebo-controlled multicenter trial of saccharomyces boulardii in irritable bowel syndrome: effect on quality of life. J Clin Gastroenterol 2011;45:679-83.

21. Guglielmetti S, Mora D, Gschwender M, Popp K. Randomised clinical trial: Bifidobacterium bifidum MIMBb75 significantly alleviates irritable bowel syndrome and improves quality of life -A double-blind, placebocontrolled study. Aliment Pharmacol Ther 2011;33:1123-32. 
22. Hong YS, Hong KS, Park MH, Ahn YT, Lee JH, Huh CS, et al. Metabonomic understanding of probiotic effects in humans with irritable bowel syndrome. J Clin Gastroenterol 2011;45:415-25.

23. Søndergaard B, Olsson J, Ohlson K, Svensson U, Bytzer P, Ekesbo R. Effects of probiotic fermented milk on symptoms and intestinal flora in patients with irritable bowel syndrome: a randomized, placebo-controlled trial. Scand J Gastroenterol 2011;46:663-72.

24. Michail S, Henche H. Gut microbiota is not modified by randomized, double-blind, placebo-controlled trial of VSL\#3 in diarrhea-predominan irritable bowel syndrome. Probiotics Antimicrob Proteins 2011;3:1-7.

25. Simrén M, Ohman L, Olsson J, Svensson U, Ohlson K, Posserud I, et al Clinical trial: the effects of a fermented milk containing three probiotic bacteria in patients with irritable bowel syndrome - A randomized, doubleblind, controlled study. Aliment Pharmacol Ther 2010;31:218-27.

26. Dolin BJ. Effects of a proprietary Bacillus coagulans preparation on symptoms of diarrhea-predominant irritable bowel syndrome. Methods Find Exp Clin Pharmacol 2009;31:655-9.

27. Hun L. Bacillus coagulans significantly improved abdominal pain and bloating in patients with IBS. Postgrad Med 2009;121:119-24.

28. Kyoung SH, Hyoun WK, Jong PI, Geun EJ, Sang GK, Hyun CJ, et al. Effect of probiotics on symptoms in Korean adults with irritable bowel syndrome. Gut Liver 2009;3:101-7.

29. Williams EA, Stimpson J, Wang D, Plummer S, Garaiova I, Barker ME, et al. Clinical trial: A multistrain probiotic preparation significantly reduces symptoms of irritable bowel syndrome in a double-blind placebo-controlled study. Aliment Pharmacol Ther 2009;29:97-103.

30. Agrawal A, Houghton LA, Morris J, Reilly B, Guyonnet D, Goupil Fevillerat N, et al. Clinical trial: The effects of a fermented milk product containing Bifidobacterium lactis DN-173 010 on abdominal distension and gastrointestinal transit in irritable bowel syndrome with constipation. Aliment Pharmacol Ther 2009;29:104-14.

31. Zeng J, Li YQ, Zuo XL, Zhen YB, Yang J, Liu CH. Clinical trial: Effect of active lactic acid bacteria on mucosal barrier function in patients with diarrhoea-predominant irritable bowel syndrome. Aliment Pharmacol Ther 2008;28:994-1002.

32. Drouault-Holowacz S, Bieuvelet S, Burckel A, Cazaubiel M, Dray X, Marteau P. A double blind randomized controlled trial of a probiotic combination in 100 patients with irritable bowel syndrome. Gastroenterol Clin Biol 2008;32:147-52.

33. Sinn DH, Song JH, Kim HJ, Lee JH, Son HJ, Chang DK, et al. Therapeutic effect of Lactobacillus acidophilus-SDC 2012, 2013 in patients with irritable bowel syndrome. Dig Dis Sci 2008;53:2714-8.

34. Guyonnet D, Chassany O, Ducrotte P, Picard C, Mouret M, Mercier $\mathrm{CH}$, et al. Effect of a fermented milk containing Bifidobacterium animalis DN-173 010 on the health-related quality of life and symptoms in irritable bowel syndrome in adults in primary care: a multicentre, randomized, double-blind, controlled trial. Aliment Pharmacol Ther 2007;26:475-86.

35. Whorwell PJ, Altringer L, Morel J, Bond Y, Charbonneau D, O'Mahony L, et al. Efficacy of an encapsulated probiotic Bifidobacterium infantis 35624 in women with irritable bowel syndrome. Am J Gastroenterol 2006;101:1581-90.

36. Kim HJ, Vazquez Roque MI, Camilleri M, Stephens D, Burton DD, Baxter K, et al. A randomized controlled trial of a probiotic combination VSL\# 3 and placebo in irritable bowel syndrome with bloating. Neurogastroenterol Motil 2005; 17:687-96.

37. Kajander K, Hatakka K, Poussa T, Färkkilä M, Korpela R. A probiotic mixture alleviates symptoms in irritable bowel syndrome patients: A controlled 6-month intervention. Aliment Pharmacol Ther 2005;22: 387-94.

38. Niv E, Naftali T, Hallak R, Vaisman N. The efficacy of Lactobacillus reuteri ATCC 55730 in the treatment of patients with irritable bowel syndrome - A double blind, placebo-controlled, randomized study. Clin Nutr 2005;24:925-31

39. Kim HJ, Camilleri M, McKinzie S, Lempke MB, Burton DD, Thomforde GM, et al. A randomized controlled trial of a probiotic, VSL\#3, on gut transit and symptoms in diarrhoea-predominant irritable bowel syndrome. Aliment Pharmacol Ther 2003;17:895-904.

40. Enck P, Zimmermann K, Menke G, Klosterhalfen S. Randomized controlled treatment trial of irritable bowel syndrome with a probiotic E.coli preparation (DSM17252) compared to placebo. Z Gastroenterol 2009;47:209-14.

41. Enck P, Zimmermann K, Menke G, Müller-Lissner S, Martens U, Klosterhalfen S. A mixture of Escherichia coli (DSM 17252) and Entero- coccus fecalis (DSM 16440) for treatment of the irritable bowel syndrome - A randomized controlled trial with primary care physicians. Neurogastroenterol Motil 2008;20:1103-9.

42. Kajander K, Krogius-Kurikka L, Rinttilä T, Karjalainen H, Palva A, Korpela R. Effects of multispecies probiotic supplementation on intestinal microbiota in irritable bowel syndrome. Aliment Pharmacol Ther 2007;26:463-73

43. Moon JT, Kim HS, Park HJ. Effects of probiotics on the intestinal gas volume score and symptoms in patients with irritable bowel syndrome. A randomized double-blind placebo-controlled study. Gastroenterology 2007;132:A688.

44. Enck P, Menke G, Zimmermann K, Martens U, Klosterhalfen S. Effective probiotic therapy of the irritable bowel syndrome (IBS): A multi-center clinical trial with primary care physicians. Gastroenterology 2007;132:A79.

45. Holowacz S, Bieuvelet S, Burckel A, Cazaubiel M, Dray X, Marteau P. A randomized controlled trial of the probiotic combination Lactibiane $^{\circledR}$ in irritable bowel syndrome, the Lactibiane® Study Group. Gastroenterology 2007;132:A371.

46. Simren M, Lindh A, Sammelsson L, Olsson J, Posserud I, Strid H, et al. Effect of yoghurt containing three probiotic bacteria in patients with irritable bowel syndrome (IBS) - A randomized, double-blind, controlled trial. Gastroenterology 2007;132:A210.

47. Kajander K, Korpela R. Clinical studies on alleviating the symptoms of irritable bowel syndrome. Asia Pac J Clin Nutr 2006;15: 576-80.

48. Simren M, Syrous A, Lindh A, Abrahamsson H. Effects of lactobacillus plantarum 299v on symptoms and rectal sensitivity in patients with irritable bowel syndrome (IBS) - A randomized, double-blind controlled trial. Gastroenterology 2006;130:A600.

49. Saggioro A. Probiotics in the treatment of irritable bowel syndrome (erratum in: J Clin Gastroenterol 2005;39:261). J Clin Gastroenterol 2004;38:S104-6.

50. Niedzielin K, Kordecki H, Birkenfeld B. A controlled, double-blind, randomized study on the efficacy of Lactobacillus plantarum $299 \mathrm{~V}$ in patients with irritable bowel syndrome. Eur J Gastroenterol Hepatol 2001;13:1143-7.

51. Gade J, Thorn P. Paraghurt for patients with irritable bowel syndrome. A controlled trial investigation from general practice. Scand J Prim Health Care 1989;7:23-6.

52. Maupas JL, Champemont P, Delforge M. Treatment of irritable bowel syndrome. Double blind trial of Saccharomyces boulardii. Medecine Chirugie Digestives 1983;12:77-9.

53. Carroll IM, Ringel-Kulka T, Siddle JP, Ringel Y. Alterations in composition and diversity of the intestinal microbiota in patients with diarrhea-predominant irritable bowel syndrome. Neurogastroenterol Motil 2012;24:521-30.

54. Chassard C, Dapoigny M, Scott KP, Crouzet L, Del'homme C, Marquet $\mathrm{P}$, et al. Functional dysbiosis within the gut microbiota of patients with constipated-irritable bowel syndrome. Aliment Pharmacol Ther 2012;35:828-38.

55. Jeffery IB, O'Toole PW, Ohman L, Claesson MJ, Deane J, Quigley EM, et al. An irritable bowel syndrome subtype defined by speciesspecific alterations in faecal microbiota. Gut 2012;61:997-1006.

56. Kassinen A, Krogius-Kurikka L, Mäkivuokko H, Tinttilä T, Paulin L, Corander J, et al. The fecal microbiota of irritable bowel syndrome patients differs significantly from that of healthy subjects. Gastroenterology 2007;133:24-33.

57. Malinen E, Rinttilä T, Kajander K, Mätö J, Kassinen A, Krogius L, et al. Analysis of the fecal microbiota of irritable bowel syndrome patients and healthy controls with real time PCR. Am J Gastroenterol 2005;100:373-82.

58. Arebi N, Gurmany S, Bullas D, Hobson A, Stagg A, Kamm M. Review article: the psychoneuroimmunology of irritable bowel syndrome - An exploration of interactions between psychological, neurological and immunological observations. Aliment Pharmacol Ther 2008; 28:830-40.

59. Parkes GC, Brostoff J, Whelan K, Sanderson JD. Gastrointestinal microbiota in irritable bowel syndrome: their role in its pathogenesis and treatment. Am J Gastrenterol 2008;103:1557-67.

60. Marteau P, Shanahan F. Basic aspects and pharmacology of probiotics: an overview of pharmacokinetics, mechanisms of action and sideeffects. Best Pract Res Clin Gastroenterol 2003;17:725-40.

61. Barbara G, Stanghellini V, De Giorgio R, Cremon C, Cottrell GS, Santini $\mathrm{D}$, et al. Activated mast cells in proximity to colonic nerves correlate with abdominal pain in irritable bowel syndrome. Gastroenterology 2004;126:693-702. 
62. Dinan TG, Quigley EMM, Ahmed SMM, Scully P, O Brien S, O’Mahonny L. Hypothalamic-Pituitary-Gut axis dysregulation in irritable bowel syndrome: plasma cytokines as a potential biomarker? Gastroenterology 2006;130:304-11.

63. Kellow JE, Azpiroz F, Delvaux M, Gebhart GF, Mertz HR, Quigley EMM. Applied principles of neurogastroenterology: Physiology/motility sensation. Gastroenterology 2006;130:1412-20.

64. Shanahan F. Irritable bowel syndrome: shifting the focus toward the gut microbiota. Gastroenterology 2007;133:340-52.

65. Barrett JS, Canale KE, Gearry RB, Irving PM, Gibson PR. Probiotic effects on intestinal fermentation patterns in patients with irritable bowel syndrome. World J Gastroenterol 2008;14:5020-4.

66. Pitz M, Cheang M, Bernstein CN. Defining the predictors of the placebo response in irritable bowel syndrome. Clin Gastroenterol Hepatol 2005;3:237-47.

67. Mearin F, Baró E, Roset M, Badía X, Zárate N, Pérez I. Clinical patterns over time in irritable bowel syndrome: symptom instability and severity variability. Am J Gastroenterol 2003;99:113-21.
68. Irvine EJ, Whitehead WE, Chey WD, Matsueda K, Shaw M, Talley NJ, et al. Design of treatment trials for functional gastrointestinal disorders. Gastroenterology 2006;130:1538-51.

69. Longstreth GF, Thompson WG, Chey WD, Houghton LA, Mearin F, Spiller RC. Functional Bowel Disorders. Gastroenterology 2006; 130:1480-91.

70. Mearin F, Roset M, Badía X, Balboa A, Baró E, Ponce J. Splitting irritable bowel syndrome: form original Rome to Rome II criteria. Am J Gastroenterol 2003;99:122-30.

71. Clarke G, Cryan JF, Dinan TG, Quigley EM. Review article: probiotics for the treatment of irritable bowel syndrome - Focus on lactic acid bacteria. Aliment Pharmacol Ther 2012;35:403-13.

72. Spiller R. Review article: probiotics and prebiotics in irritable bowel syndrome. Aliment Pharmacol Ther 2008;28:385-96.

73. Ki Cha B, Mun Jung S, Hwan Choi C, Song ID, Woong Lee H, Joon Kim $\mathrm{H}$, et al. The effect of a multispecies probiotic mixture on the symptoms and fecal microbiota in diarrhea-dominant irritable bowel syndrome: A randomized, double-blind, placebo-controlled trial. J Clin Gastroenterol 2012;46:220-7. 